\title{
Overexpansion of the SAPIEN 3 Transcatheter Heart Valve in a Tricuspid Aortic Valve with Huge Annulus
}

\author{
Wen-Pin Hsiao ${ }^{1}$, Mao Shin $\mathrm{Lin}^{2}$, Hsien Li Kao ${ }^{2}$, Ying-Hsien Chen², and Yih-Sharng Chen ${ }^{3}$ \\ ${ }^{1}$ Affiliation not available \\ ${ }^{2}$ National Taiwan University Hospital \\ ${ }^{3}$ Natl Taiwan Univ Hosp
}

April 25, 2021

\begin{abstract}
Transcatheter aortic valve replacement (TAVR) has become a treatment alternative for patients with severe aortic stenosis. As broadened indications and increasing clinical demand, the population referred for TAVR will become much more heterogeneous and anatomically challenging. Herein, we report an 88-year-old man with severe aortic stenosis and huge aortic annulus (annular area $831.8 \mathrm{~mm} 2$ ) successfully treated with overexpansion of a $29 \mathrm{~mm}$ Edwards SAPIEN 3 transcatheter heart valve.
\end{abstract}

Overexpansion of the SAPIEN 3 Transcatheter Heart Valve in a Tricuspid Aortic Valve with Huge Annulus

Wen-Pin Hsiao, $\mathrm{MD}^{1}$, Hsien-Li Kao, $\mathrm{MD}^{2}$, Ying-Hsien Chen, $\mathrm{MD}^{2}$, Yih-Sharng Chen, MD, $\mathrm{PhD}^{3}$, Mao-Shin Lin, $\mathrm{MD}, \mathrm{PhD}^{2}$

${ }^{1}$ Department of Internal Medicine, Cardinal Tien Hospital, New Taipei City, Taiwan

${ }^{2}$ Department of Internal Medicine, ${ }^{3}$ Department of Surgery, National Taiwan University Hospital, Taipei, Taiwan

Corresponding author: Mao-Shin Lin, MD, $\mathrm{PhD}$

Department of Internal Medicine, National Taiwan University Hospital,

No. 7, Chung-Shan South Road, Taipei, Taiwan.

Telephone: 886-2-23123456-65211

FAX: 886-2-23216938

E-mail: linmaoshin@gmail.com

\begin{abstract}
Transcatheter aortic valve replacement (TAVR) has become a treatment alternative for patients with severe aortic stenosis. As broadened indications and increasing clinical demand, the population referred for TAVR will become much more heterogeneous and anatomically challenging. Herein, we report an 88-year-old man with severe aortic stenosis and huge aortic annulus (annular area $831.8 \mathrm{~mm}^{2}$ ) successfully treated with overexpansion of a $29 \mathrm{~mm}$ Edwards SAPIEN 3 transcatheter heart valve.
\end{abstract}

Key wards: transcatheter aortic valve replacement (TAVR), large annulus, overexpansion of transcatheter heart valve 


\section{INTROTUCTION}

Transcatheter aortic valve replacement (TAVR) has revolutionized the treatment of symptomatic severe aortic stenosis (AS) (1). In the last decade, TAVR was approved from inoperable to low surgical risk patients based on the results of landmark randomized trials (2-5). As TAVR indications continue to expand, along with the advancement of devices and technical skills, more patients with poor vascular access or challenging anatomy once considered illegible for TAVR may be attempted.

Because of the physical limitation of currently available transcatheter heart valves (THV) sizes, AS patient with extremely large aortic annulus (ie., area $>683 \mathrm{~mm}^{2}$ or perimeter $>94 \mathrm{~mm}$ ) is contraindicated for TAVR. However, several case series have demonstrated the feasibility of over-expansion of a $29 \mathrm{~mm}$ SAPIEN 3 valve (Edwards Lifesciences, Irvine, CA, USA) in patients with aortic annulus area between $683^{\sim} 800 \mathrm{~mm}^{2}$ (6-9). We report the following successful THV implantation in a severe tricuspid AS patient with aortic annulus area $>800 \mathrm{~mm}^{2}$, the largest in the literature to the best of our knowledge.

\section{CASE DESCRIPTION:}

An 89-year-old man with a history of hypertension and type 2 diabetes mellitus presented with shortness of breath and bilateral legs edema 2 weeks prior to evaluation. Severe symptomatic aortic stenosis was confirmed in other hospital, and the patient was referred to our institution for TAVR. Chest X-ray revealed prominent lung edema with bilateral pleural effusion. Transthoracic echocardiography demonstrated poor left ventricular systolic function (left ventricular ejection fraction: $36.4 \%$ ) and tricuspid configuration aortic valve with severe stenosis (peak velocity: $4.2 \mathrm{~m} / \mathrm{s}$; mean transvalvular pressure gradient: $41 \mathrm{mmHg}$; estimated valve area: $0.53 \mathrm{~cm}^{2}$ ). He was dependent on intravenous infusion of inotropic agents, and was deemed at high risk for surgical aortic valve replacement with predicted surgical mortality of $8.234 \%$ by STS-PROM (Society of Thoracic Surgeons-Predicted Risk of Mortality) and $17.37 \%$ by EuroSCORE (European System for Cardiac Operative Risk Evaluation-II). Multidetector computed tomography (CT) showed a huge annulus measuring $37.9 \times 27.8 \mathrm{~mm}$ in diameter and an area of $831.8 \mathrm{~mm}^{2}$ (Figure 1). The measured annulus size exceeds the upper limit of both the commercially available self-expanding and balloon-expanding THV in our institution. In view of the patients age and high surgical risk, the decision was made by the heart team to proceed with TAVR by over-expansion of $29 \mathrm{~mm}$ SAPIEN 3 THV.

The procedure was performed under conscious sedation and right femoral access. Temporary pacemaker was placed in right ventricle via internal jugular vein. A $29 \mathrm{~mm}$ Edwards SAPIEN S3 THV was inserted and expanded by overfilling of the deployment balloon with $4 \mathrm{ml}$ of additional volume under rapid pacing. The post-TAVR aortography revealed a well-positioned THV with mild paravalvular regurgitation (Figure 2). The maximal diameter of post-deployment THV was $32.23 \mathrm{~mm}$ by quantitative fluoroscopy analysis (Figure 3). The procedure was uncomplicated and there was no new conduction disturbance requiring permanent pacemaker. The patient was discharged 6 days after TAVR. The 1-month follow-up transthoracic echocardiography showed well-functioning THV (peak velocity $=1.9 \mathrm{~m} / \mathrm{s} ;$ mean transvalvular gradient $=7.9$ $\mathrm{mmHg}$; estimated valve area $=2.1 \mathrm{~cm}^{2}$ ) with a mild paravalvular leakage (Figure 4).

\section{DISCUSSION:}

As the indications for TAVR are expanding, operators are faced with more complex and challenging anatomy. In the present case, we demonstrated that TAVR is feasible by over-expansion of $29 \mathrm{~mm}$ SAPIEN 3 THV in a tricuspid AS patient with an annulus area exceeding $800 \mathrm{~mm}^{2}$. Shivaraju et al (6) first described the over-expansion technique in an AS patient with annulus area of $742 \mathrm{~mm}^{2}$, with $4 \mathrm{~mL}$ of additional volume in the delivery balloon. Mathur et al (7) and Barr et al (8) then reported the results of TAVR in 8 patients, with aortic annulus area ranging from $691.0 \mathrm{~mm}^{2}$ to $800.0 \mathrm{~mm}^{2}$, using the same technique. To our best knowledge, there has been only 1 reported TAVR case with annulus area exceeding $800 \mathrm{~mm}$, but in a bicuspid aortic valve (10). In contrast, our case valve was tricuspid configuration and the implant depth was at the annulus, thus resulting in the largest over-expansion of SAPIEN S3 THV ever reported.

Nominal volume $29 \mathrm{~mm}$ SAPIEN 3 THV deployment will definitely result in significant valve under-sizing in 
our patient. Additional $4 \mathrm{~mL}$ volume expansion on THV deployment, according to calculation, will still result in $-9.8 \%$ undersize. In our pre-TAVR planning, $5 \mathrm{~mL}$ additional volume post-dilatation will be performed if significant paravalvular leakage (PVL) was noted after deployment. This will reduce the estimated undersize to $-6.7 \%$. With the new frame geometry and outer skirt design of the SAPIEN 3 THV, however, even this maneuver was unnecessary. In recent analysis of SAPIEN 3 study (11), rate of PVL was low even with SAPIEN 3 THV undersized up to $-5 \%$.

The actual safe limit of over-expansion for SAPEIN 3 THV, however, are still unknown. Over-expansion may prohibit proper leaflet coaptation, increase the risk of valve dislodgement, and incur positioning challenges due to excessive frame shortening. The design of longer leaflets might allow the SAPIEN 3 THV to be more tolerant to over-expansion, and accommodate larger annulus sizes without resulting in significant central aortic regurgitation. Sengupta et al (12) reported 105 large annulus AS patients, with mean annulus area of $721.3+-36.1 \mathrm{~mm}^{2}$, implanted with SAPIEN $3 \mathrm{THV}$. The rate of [?]moderate transvalvular aortic regurgitation and PVL were $0 \%$ and $4.3 \%$ respectively at 1 year. Miyasaka et al (9) also demonstrated the feasibility of SAPIEN 3 THV in 30 patients with large annulus (mean annulus area $737.3+-54.7 \mathrm{~mm}^{2}$ ), with similar procedural outcomes and 1-year mortality compared to those with regular annulus (area $<683.0 \mathrm{~mm}^{2}$ ). These results, along with the present case experience, may provide evidence for the use of over-expanded 29mm SAPIEN 3 THV in patients with extremely large annulus. Longer term follow-up in a larger patient population is mandatory to determine its durability.

\section{Conclusion:}

We demonstrate that TAVR using over-expanded $29 \mathrm{~mm}$ SAPIEN 3 THV in a patient with annuls areas of $831.8 \mathrm{~mm}^{2}$ is safe and feasible.

\section{REFERENCE}

1. Baumgartner H, Falk V, Bax JJ, De Bonis M, Hamm C, Holm PJ, Iung B, Lancellotti P, Lansac E, Rodriguez Munoz D, Rosenhek R, Sjogren J, Tornos Mas P, Vahanian A, Walther T, Wendler O, Windecker S, Zamorano JL; ESC Scientific Document Group. 2017 ESC/EACTS guidelines for the management of valvular heart disease. Eur Heart J. 2017;38(36):2739-2791.

2. Smith CR, Leon MB, Mack MJ, Miller DC, Moses JW, Svensson LG, Tuzcu EM, Webb JG, Fontana GP, Makkar RR, Williams M, Dewey T, Kapadia S, Babaliaros V, Thourani VH, Corso P, Pichard AD, Bavaria JE, Herrmann HC, Akin JJ, Anderson WN, Wang D, Pocock SJ; PARTNER Trial Investigators. Transcatheter versus surgical aortic-valve replacement in high-risk patients. N Engl J Med. 2011;364(23):2187-98.

3. Leon MB, Smith CR, Mack MJ, Makkar RR, Svensson LG, Kodali SK, Thourani VH, Tuzcu EM, Miller DC, Herrmann HC, Doshi D, Cohen DJ, Pichard AD, Kapadia S, Dewey T, Babaliaros V, Szeto WY, Williams MR, Kereiakes D, Zajarias A, Greason KL, Whisenant BK, Hodson RW, Moses JW, Trento A, Brown DL, Fearon WF, Pibarot P, Hahn RT, Jaber WA, Anderson WN, Alu MC, Webb JG; PARTNER 2 Investigators. Transcatheter or surgical aortic-valve replacement in intermediate-risk patients. N Engl J Med. 2016;374(17):1609-20.

4. Mack MJ, Leon MB, Thourani VH, Makkar R, Kodali SK, Russo M, Kapadia SR, Malaisrie SC, Cohen DJ, Pibarot P, Leipsic J, Hahn RT, Blanke P, Williams MR, McCabe JM, Brown DL, Babaliaros V, Goldman S, Szeto WY, Genereux P, Pershad A, Pocock SJ, Alu MC, Webb JG, Smith CR; PARTNER 3 Investigators. Transcatheter aortic-valve replacement with a balloon-expandable valve in low-risk patients. N Engl J Med. 2019;380(18):1695-1705.

5. Popma JJ, Deeb GM, Yakubov SJ, Mumtaz M, Gada H, O’Hair D, Bajwa T, Heiser JC, Merhi W, Kleiman NS, Askew J, Sorajja P, Rovin J, Chetcuti SJ, Adams DH, Teirstein PS, Zorn GL 3rd, Forrest JK, Tchetche D, Resar J, Walton A, Piazza N, Ramlawi B, Robinson N, Petrossian G, Gleason TG, Oh JK, Boulware MJ, Qiao H, Mugglin AS, Reardon MJ; Evolut Low Risk Trial Investigators. Transcatheter aortic-valve replacement with a self-expanding valve in low-risk patients. N Engl J Med. 2019;380(18):1706-1715.

6. Shivaraju A, Kodali S, Thilo C, Ott I, Schunkert H, von Scheidt W, Leon MB, Kastrati A, Kasel AM. 
Overexpansion of the SAPIEN 3 Transcatheter Heart Valve: A Feasibility Study. JACC Cardiovasc Interv. 2015;8(15):2041-2043

7. Mathur M, McCabe JM, Aldea G, Pal J, Don CW. Overexpansion of the $29 \mathrm{~mm}$ SAPIEN 3 transcatheter heart valve in patients with large aortic annuli (area $>683 \mathrm{~mm} 2)$ : A case series. Catheter Cardiovasc Interv. $2018 ; 91(6): 1149-1156$.

8. Barr P, Ormiston J, Stewart J, Nand P, Ramanathan T, Webster M. Transcatheter Aortic Valve Implantation In Patients With a Large Aortic Annulus. Heart Lung Circ. 2018 ;27(3):e11-e14.

9. Miyasaka M, Yoon SH, Sharma RP, Maeno Y, Jaideep S, Taguri M, Kato S, Kawamori H, Nomura T, Ochiai T, Nemanpour S, Chakravarty T, Nakamura M, Wen C, Makkar R. Clinical Outcomes of Transcatheter Aortic Valve Implantation in Patients With Extremely Large Annulus and SAPIEN 3 Dimensions Based on Post-Procedural Computed Tomography. Circ J. 2019 ;83(3):672-680.

10. Buchanan KD, Rogers T, Shults C, Ben-Dor I, Satler LF, Waksman R. Successful transcatheter aortic valve replacement in an oversized $800 \mathrm{~mm}^{2}$ annulus and bicuspid aortic valve. Cardiovasc Revasc Med. 2018;19(8S):65-67.

11. Blanke P. Influence of computed tomography-based over-sizing on the incidence of para-valvular regurgitation of a new generation transcatheter valve: Early results of the Intermediate Risk S3 Cohort PARTNER II trial. Presented at EuroPCR 2015. May 20, 2015, Paris, France

12. Sengupta A, Zaid S, Kamioka N, Terre J, Miyasaka M, Hirji SA, Hensey M, Geloo N, Petrossian G, Robinson N, Sarin E, Ryan L, Yoon SH, Tan CW, Khalique OK, Kodali SK, Kaneko T, Shah PB, Wong SC, Salemi A, Sharma K, Kozina JA, Szerlip MA, Don CW, Gafoor S, Zhang M, Newhart Z, Kapadia SR, Mick SL, Krishnaswamy A, Kini A, Ahmad H, Lansman SL, Mack MJ, Webb JG, Babaliaros V, Thourani VH, Makkar RR, Leon MB, George I, Tang GHL.. Mid-term outcomes of transcatheter aortic valve replacement in extremely large annuli with edwards SAPIEN 3 valve. JACC Cardiovasc Interv. 2020 13(2):210-216.

\section{FIGURE LEGEND}

Figure 1. Computed tomography measurement of aortic annulus in $35 \%$ cardiac cycle demonstrating annulus area of $831.8 \mathrm{~mm}^{2}$ and diameter of $37.9 \times 27.8 \mathrm{~mm}$.

Figure 2. Aortogram immediately obtained following 29-mm SAPIEN 3 transcatheter heart valve demonstrated well-positioned valve with mild paravalvular regurgitation.

Figure 3. Quantitative fluoroscopy analysis showed the inflow diameter of over-expanded transcatheter heart valve was $32.23 \mathrm{~mm}$.

Figure 4. 1-month follow-up transthoracic echocardiography showed the well-functioning transcatheter heart valve with a mild paravalvular leakage and no transvalvular regurgitation. 

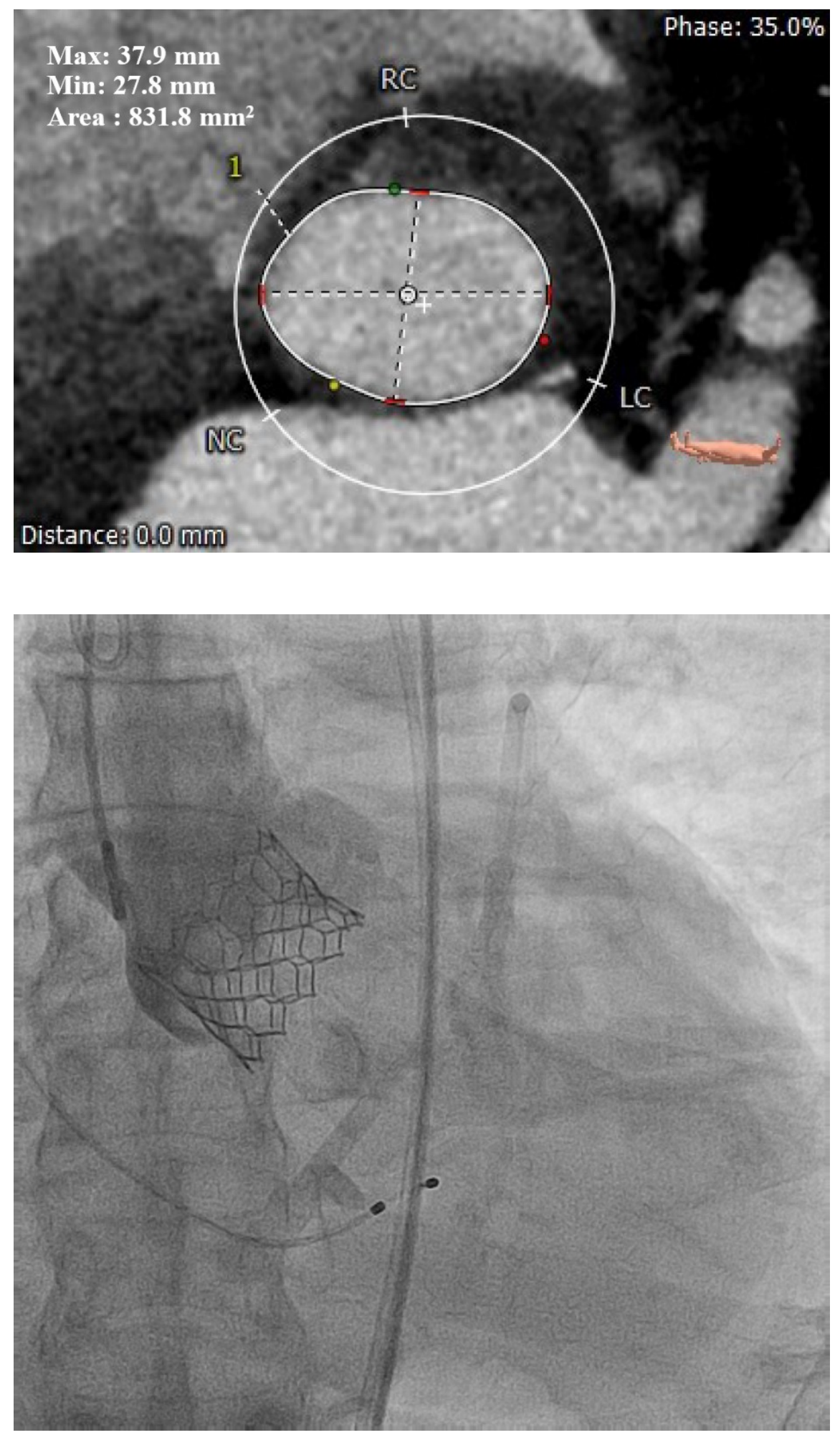

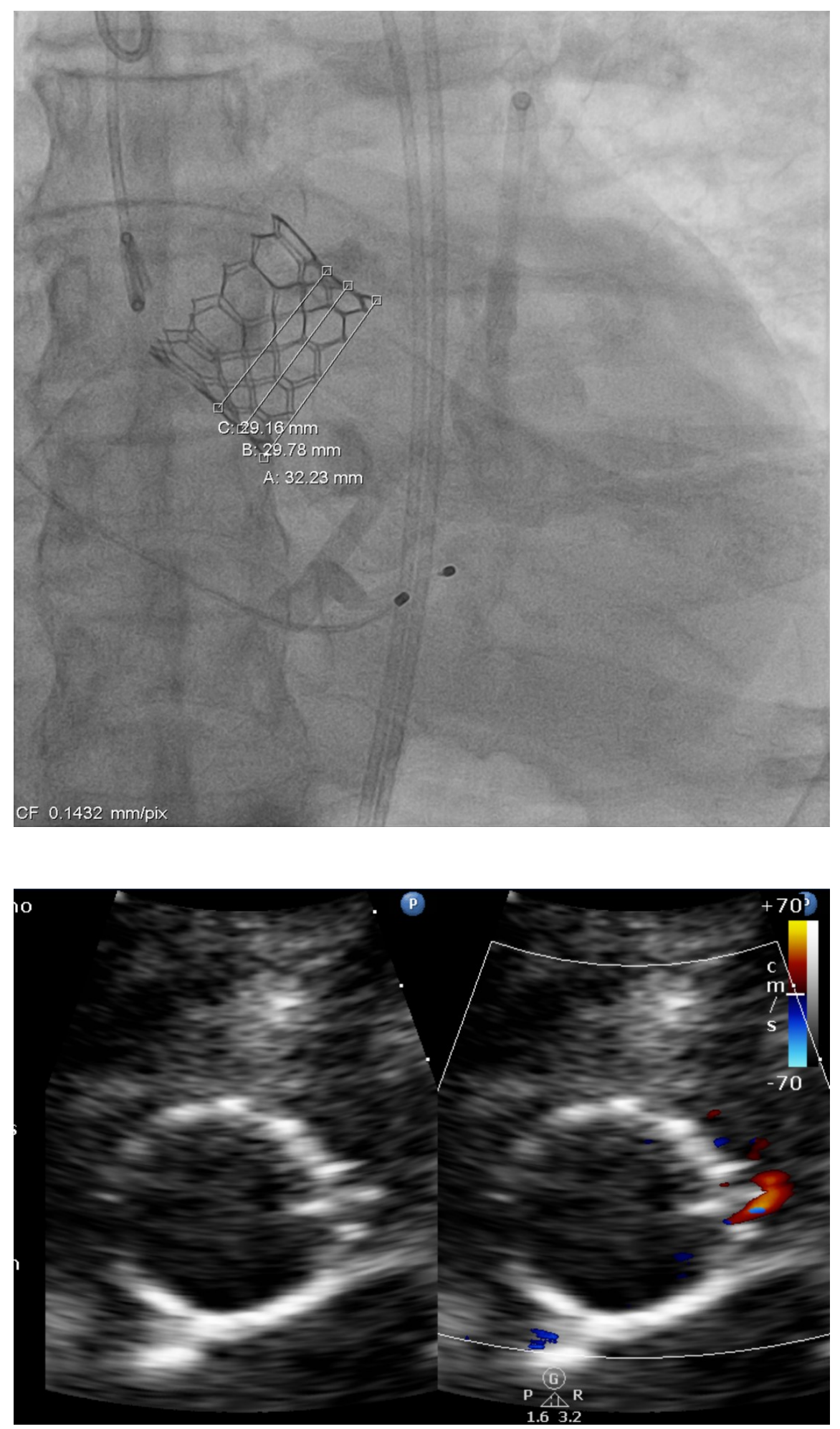